\title{
PARA LO QUE HA QUEDADO VARGAS VILA
}

\author{
POR \\ José Luis DíAz-Granados \\ Escritor colombiano
}

Si acaso usted, buscando allí su fosa, dice de Vargas Vila cualquier cosa... ( Para lo que ha quedado Vargas Vila!).

Luis Carlos López, "Frente a mi casa" (72)

Han transcurrido ya ochenta años del fallecimiento de José María Vargas Vila, y los críticos (si es que hay quienes aún se interesen realmente por este polémico hombre de letras), no han logrado encasillarlo en género literario alguno. No encaja como novelista a pesar de que en su tiempo sus devotos lectores, que fueron millares regados por España y las Américas, devoraban sus novelas con más sentido mórbido que estético. Como ensayista dista muchísimo de lograr la profundidad y el dominio temático que en su tiempo mostraron los más notables prosistas del género como José Martí (1853-1895), Baldomero Sanín Cano (1861-1957) o Alfonso Reyes (1889-1959). Como periodista, Vargas Vila era más lírico en eufonías emocionales que informador veraz y objetivo. Como historiador era nulo de toda nulidad y como poeta nada qué ver con las musas o los duendes de la inspiración.

La posteridad lo ha recordado de manera unánime como fogoso polemista. Se ufanaba, desde luego, de su facilidad natural para la blasfemia, el ataque directo y el sistemático combate contra quienes para él eran los representantes de la ignominia, la injusticia y la barbarie. O sea, el naciente imperialismo de los Estados Unidos, la Iglesia Católica Romana y la Regeneración: el régimen conservador y clerical impuesto en Colombia con la Constitución de 1886, luego de la traición y el transfuguismo del antiguo jefe radical (liberal y masón) Rafael Núñez (1825-1894).

$$
* * *
$$

Como ninguna otra sociedad latinoamericana, Colombia ha sido tierra fértil para los blasfemos, los transgresores, los panfletarios y los insultadores, como si en el fondo del alma de sus habitantes se ocultaran, bajo distintas formas de represión mental, las 
más bajas y secretas pasiones negativas, pasiones anegadas de odio y resentimiento, nutridas con los más horrendos borborigmos y retorcijones intestinales por obra y gracia de una supuesta institucionalidad mal cimentada, con querencias e ideologías arraigadas bajo inquisidora imposición y creencias pegadas con babas en diversos aspectos del acontecer cotidiano.

No son pocos los letrados rebeldes -unos ilustres, otros menos-que sobresalen por sus prosas sarcásticas, incendiarias, escandalosas y panfletarias. Podríamos citar a un Fernando González (1895-1964), filósofo antioqueño, nihilista y contestatario, quien atacó presidentes, personajes del notablato local y juristas que tachaba de tinterillos. Odiaba con todas las fuerzas de su alma al general Francisco de Paula Santander por sus traiciones al Libertador Simón Bolívar, por su doble moral y por su rabulismo leguleyo. A las religiosas que lo expulsaron en la escuela primaria las calificó de "iHermanas cagonas!" y a los indios que se comieron a unos misioneros capuchinos los fustigó por el mal gusto que tuvieron al acudir a tan desagradables viandas. Iconoclasta y pugnaz, en opinión de Ernesto Ochoa Moreno, "se enfrentó a la mentira colombiana y sus contemporáneos no le perdonaron la franqueza con que habló. Por eso fue excomulgado y olvidado (2D). Sin embargo [agrega Ochoa Moreno] su verdad, que golpea y azota en sus libros, está aún tan viva que ha cobrado vigencia con los años" (2D). La verdad es que pasado cierto tiempo, estos "demonios" suelen ser santificados. Prueba de ello es que en 2006, el presidente Álvaro Uribe Vélez sancionó la Ley 1068, "por la cual la Nación exalta la memoria, vida y obra del filósofo antioqueño Fernando González".

Otros iconoclastas fueron los también antioqueños Porfirio Barba-Jacob, Gonzalo Arango y Fernando Vallejo, entre otros.

Porfirio Barba-Jacob (1883-1942), uno de los más notables poetas colombianos de todos los tiempos, se destacó también como uno de los más amargos prosistas de su tiempo, periodista panfletario y mercenario que vivió varias veces al servicio de tiranuelos centroamericanos. Para Darío Jaramillo Agudelo, excelente poeta y paisano suyo -ambos nacieron en la población antioqueña de Santa Rosa de Osos-, Barba-Jacob "no era propiamente un santo, ni alcanzaba la categoría de hombre decente, ni siquiera fue un buen tipo" ("Porfirio Barba-Jacob"). Y además, "era una pluma a sueldo, un cínico, un sablista, un vividor, un vicioso, en fin, un pequeño truhán difícil de fiar [... que] sonríe y destila hiel" ("Porfirio Barba-Jacob").

Gonzalo Arango (1932-1976), escritor antioqueño, fundador del movimiento Nadaísta en 1958, crítico del sistema reinante (denominado El Frente Nacional, en el cual liberales y conservadores se alternaron el poder durante dos décadas, luego de una histórica reconciliación que puso fin a ciento cincuenta años de feroces guerras fratricidas), y quien en sus poemas, prosas y sermones invitaba a matar a los padres, dinamitar el busto de María, la heroína de la novela de Jorge Isaacs, profanar hostias y a admirar bandidos, pero que en realidad era más santo que demonio.

Revista Iberoamericana, Vol. LXXXI, Núm. 252, Julio-Septiembre 2015, $731-739$ ISSN 0034-9631 (Impreso)

ISSN 2154-4794 (Electrónico) 
Pero Fernando Vallejo (1942) es quizás el que ha ido más lejos que sus antecesores pues ha herido las alegorías más sensibles de sus coterráneos de Antioquia: por ejemplo, a la madre, a quien apoda "La Loca" en El desbarrancadero (2002), a la Iglesia Católica -en todos sus libros, pero especialmente en La puta de Babilonia (2006)- y a los patriarcas y empresarios de Medellín, a los afrocolombianos y a los conductores de taxi de la capital de la Montaña y sus alrededores. En sus charlas y conferencias repite la creencia de que en Antioquia no se ha publicado jamás una obra literaria de valor.

Y quizás, en atención a la sentencia de André Bretón en el sentido de que es "deber de todo artista odiar a su país creativamente" (Vásquez 130), el ensayista Rafael Gutiérrez Girardot (1928-2005) encontró razones válidas para odiar a Colombia atacando, desde luego de manera crítica, a un nacionalismo que considera, usando las palabras de Juan Gabriel Vásquez, "soso, ciego y estúpido, y que siempre, sin que se sepa bien por qué, se vuelve pequeño fundamentalismo o chovinismo ingenuo y peligroso" (130-131).

Pero sin ninguna duda, el más connotado de los letrados blasfemos de Colombia es José María Vargas Vila. Ya lo hemos dicho: somos tierra fértil para estos terribles demonios y las razones para su existencia posiblemente sean válidas. Mientras en la elitista y simuladora Bogotá los políticos tradicionalistas y clericales, los presidentes gramáticos y los parlamentarios latinistas y de elocuencia clásica dominan la cultura, en la provincia lo hacen los escritores rebeldes y los panfletarios. Al respecto, la ensayista y narradora Helena Araújo escribe sobre el célebre insultador:

El primero en la lista y el más célebre es José María Vargas Vila (1860-1933), quien se exilia desde muy joven y escribe con furia y desesperación durante interminables viajes. Panfletario itinerante, deja entre periodismo y narrativa cerca de un centenar de obras. Protestando contra un gobierno despótico y clerical, colabora en la prensa continental y se hace amigo de Martí, Darío, Vasconcelos, Mistral. En Colombia, se leen clandestinamente sus novelas, dramas hiperbólicos y folletinescos que constituyen por su sensualismo lujurioso una tentación para un público habituado a lecturas más púdicas. Su mayor logro, sin embargo, está en el panfleto. Es entonces que su elocuencia se desata: escribe como hablando, o mejor dicho insultando. Maestro del escarnio, de la injuria, del sarcasmo, "en una época de orgías verbales se convierte en el sumo sacerdote". Y gana progresivamente audiencia. En México, Venezuela, Chile, Argentina, se le aclama y se le publica. Él mismo, con su excentricidad y megalomanía contribuye a su propia leyenda. Aunque ostente gustos extravagantes y poco accesibles a las clases trabajadoras que con tanta pasión defiende, el pueblo colombiano lo lee con fervor. Célebre -entre muchas- es la anécdota de un boga del río Magdalena que mata a un congénere a machetazos porque se atreve a hablarle contra Vargas Vila. (37)

Revista Iberoamericana, Vol. LXXXI, Núm. 252, Julio-Septiembre 2015, 731-739 
Vargas Vila era en verdad un militante apasionado de las causas de la libertad y la justicia social. Odiaba toda forma de opresión y sentía aversión arterial hacia los tiranos. Es posible que más que un liberal o un radical intransigente, este polémico personaje fuese un anarquista, un nihilista, un desbocado adversario de todas las formas de autoridad y poder.

Pero antes que todo eso, Vargas Vila era un hombre de pluma que gozaba con todas las energías de su corazón derramando a torrentes las obsesiones, amarguras y agonías delirantes que se estrangulaban en lo más profundo de su alma. Esta obsesiva condición de infatigable exorcismo se nota a medida que el lector avanza en el recorrido de sus peroratas ultrajantes y nerviosas, escritas casi en verso, con prosa cortada a manera de frases súbitas y bruscas en donde injuriaba, insultaba, maldecía y disparaba contra los déspotas de todas las condiciones y poderes, los traidores a lo Rafael Núñez con sus camaradas radicales, las jerarquías católicas, los escritores que vendían sus plumas a los reyezuelos de turno y en especial, al naciente imperialismo que desde Washington ejercía la "Política del garrote" mediante invasiones cruentas a México (con el consabido apoderamiento de parte de su territorio), a Guatemala, Nicaragua, Honduras y la usurpación del istmo de Panamá a la república que vio nacer al polemista.

Su carácter energúmeno, sin embargo, cegaba el espíritu de solidaridad con sus colegas. Es célebre su diatriba contra el poeta peruano José Santos Chocano (1875-1934) cuando fue condenado a la pena capital en 1920 por haber servido como secretario del dictador guatemalteco Manuel Estrada Cabrera (1857-1924). A punto de ser decapitado, los más destacados poetas, novelistas, ensayistas y académicos de Europa y las Américas elevaron sus voces de protesta ante los verdugos del autor de Alma-América, con la arrogante excepción del insultador colombiano, quien se limitó a expresar: "Los dioses no consintieron que Santos Chocano deshonrara el patíbulo, muriendo en él. Ahí está vivo, después de haber fatigado la infamia". Frase lapidaria que le hizo exclamar al irónico Jorge Luis Borges: "Es la injuria más espléndida que conozco: injuria tanto más singular si consideramos que es el único roce de su autor con la literatura" (cit. en Borges 195).

Años atrás, en un ataque de furia, Vargas Vila había arremetido contra Rubén Darío (1867-1916), el genial nicaragüense, por haber aceptado de manos del presidente Rafael Núñez el nombramiento de cónsul de Colombia en Buenos Aires, lo que por cierto marcó la época más fecunda y feliz del príncipe de los poetas hispanoamericanos. Con Darío se reconcilió, sin embargo, poco después, cuando se rumoró la muerte de Vargas Vila y aquel escribió una página memorable que conmovió al polemista colombiano. Debo poner de presente que en 1904, José Santos Zelaya, primer mandatario de Nicaragua, los nombró a los dos como miembros de la Comisión de Límites con Honduras ante el reino de España.

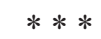

Revista Iberoamericana, Vol. LXXXI, Núm. 252, Julio-Septiembre 2015, $731-739$ ISSN 0034-9631 (Impreso)

ISSN 2154-4794 (Electrónico) 
La obra de Vargas Vila abarca cerca del centenar de libros. Por cierto, su editor en Barcelona le pagaba por adelantado y el autor vivía como un potentado en hoteles y mansiones de España, Francia y Suiza. Antes de dedicarse a las letras, Vargas Vila había injuriado al presbítero Tomás Escobar; luego se había enrolado en las fuerzas revolucionarias lideradas por el general Santos Acosta (1827-1901). Más tarde fue maestro de escuela en varias poblaciones del Tolima y Cundinamarca. En Bogotá, conoció al poeta José Asunción Silva (1865-1896). Fue amigo de los modernistas, especialmente de José Martí, Rufino Blanco Fombona (1874-1944) y Enrique GómezCarrillo (1873-1927). En 1878 había fundado la revista Los Refractarios con Juan de Dios “El Indio" Uribe (1859-1900) y Diógenes Arrieta (1848-1897); fundó también la Revista Hispano-América, donde publicó la mayoría de los cuentos que integraron su libro Copos de espuma, y la revista Némesis en Nueva York, la ciudad donde iniciaría la escritura del virulento panfleto antinorteamericano titulado Ante los bárbaros. Los Estados Unidos y la guerra. El yanki: he ahi el enemigo.

Sus libros eran una summa de narraciones, lírica altisonante y desenfrenada -al decir del crítico Carlos García Prada-, crónicas, diatriba, discursos, diarios de viaje, epístolas y notas periodísticas. Pero cada obra suya era recibida en su momento con regocijo multitudinario. La popularidad de que gozó en vida no rivalizó con la de ningún contemporáneo suyo. Dicen que alguna vez, ya viviendo en Barcelona, "rico y famoso," Gabriel García Márquez exclamó: “-¡Yo soy el Vargas Vila de mi generación!”

Cada libro publicado por el panfletario era recibido por sus seguidores como una llaga incandescente. Su trilogía compuesta por Lirio blanco, Lirio rojo y Lirio negro, fue sinónimo de combates verbales y polémicas a todo lo largo y ancho del continente americano. Y en ese estilo artificioso y afectado - con todos los defectos de los modernistas y muy pocas de sus virtudes- fue pergeñando y publicando - a veces hasta tres o más por año-cada uno de sus cien libros provocadores y cáusticos.

Los césares de la decadencia (1907) es una colección de puñaladas contra Rafael Núñez y la Regeneración; en Alba roja (1901), el protagonista desentierra la tumba de la madre, intuye el sitio de su oreja y recostado sobre ella le cuenta los más profundos secretos de su corazón; "Sombra y sangre", un capítulo de su libro titulado Pretéritas (1915), es una diatriba contra el patíbulo; Verbo de admonición y de combate (1905), contra los autores de genocidios en el continente; La muerte del cóndor (1914), trata sobre el asesinato de Eloy Alfaro y contra los políticos supuestamente amigos que lo traicionaron; La república romana (1909), contra la aristocracia, el militarismo y la esclavitud; "Las aves negras", también parte de Pretéritas, contra los jesuitas; Los providenciales (1892), contra los caudillos bárbaros de América Latina, y así, demoledores e iconoclastas, son Los divinos y los humanos (1904), El canto de las sirenas en los mares de la historia (1906?), Hombres y crímenes del Capitolio (1910?), El imperio romano (1912?), Los estetas de Teópolis (1918), La ubre de la loba (1918?), Los Soviets

Revista Iberoamericana, Vol. LXXXI, Núm. 252, Julio-Septiembre 2015, 731-739 ISSN 0034-9631 (Impreso)

ISSN 2154-4794 (Electrónico) 
(1926) y Sombras de águilas (1916?), entre otros tratados de la repugnancia, el escarnio, el vituperio y la diatriba.

$$
* * *
$$

Como si lo anterior fuera poco, el propio Vargas Vila se jactaba de que sus libros estimulaban el suicidio. Se refería a Ibis (1917) como "un libro de fatalidad" que había ocasionado "diecisiete suicidios", además de haber disuelto múltiples noviazgos y matrimonios, fomentado las fugas del hogar estable, pero sobre todo por haber perturbado centenares de conciencias tranquilas. Sentíase orgulloso de ser el mensajero de la desolación y la muerte, los amores prohibidos, el pesimismo, el delirio y el hastío. Para él, la mujer es la víbora venenosa que sólo sirve para henchir de placer lúbrico al macho despótico, pero que a su vez es trastornado en su voluntad y en su carácter. Como diría Jonatás el Rabino en el poema misógino "La Palabra de Dios" de Guillermo Valencia:

\footnotetext{
Nunca bebas, me dijo, del licor femenino, que es licor de mandrágoras y destila demencia. Si lo bebes, al punto morirá tu conciencia, volarán tus canciones y errarás el camino. (155)
}

Para el perenne blasfemo, la purulencia del mundo está concentrada en la Iglesia Católica, bajo las sotanas eclesiásticas. Se sentía, como buen radical de provincia, capaz de, al decir popular, "ahorcar al último cura con la tripa de la última monja", pues todos ellos pertenecían a una misma "tribu apostólica" de "sátrapas epilépticos" (Alba roja, XII). Sin embargo, la pústula de América Latina, de "Nuestra América" como la denominaba su amigo Martí, era el imperialismo norteamericano. El "yanqui", como lo llamaba el autor, era la representación moderna del dragón rapaz y amenazante de los hombres y los pueblos. Al igual que el Apóstol de Cuba, vivió “en las entrañas del monstruo" y a él dedicó sus más afilados libelos.

Pero, al mismo tiempo, su patria era la víctima horrorizada de la más putrefacta de las dinastías políticas: la Regeneración, que era ni más ni menos la encarnación de la traición, el oscurantismo, la hipocresía y la concupiscencia moral y física entronizada en la Quinta del Cabrero, desde donde Rafael Núñez gobernaba dictatorialmente a Colombia. Para Núñez y sus áulicos, Vargas Vila no ahorró ataques, ofensas ni oprobios verbales, pues para él, ellos eran peores que las serpientes más abominables o que los más inmundos chacales, que se revolcaban en el fango de sus propias heces.

De manera que juzgar una obra a la luz de la literatura bajo la sombra de estos elementos moldeados por el odio y la injuria, desemboca en un pálido balance de vacíos críticos. A eso habría que agregar que tras tantas toneladas de basura farragosa sólo se vislumbra una pobre literatura frágil e insustancial. Nada tenía qué ver la desmesurada

Revista Iberoamericana, Vol. LXXXI, Núm. 252, Julio-Septiembre 2015, $731-739$ ISSN 0034-9631 (Impreso) ISSN 2154-4794 (Electrónico) 
obra vargasviliana (o vargasbiliosa) con las Catilinarias de Marco Tulio Cicerón, con las invectivas infernales del Dante Alighieri, con las sátiras y letrillas de Quevedo o de Góngora o con los libelos elocuentes de don Juan Montalvo.

El genio creador, el ángel, el duende imaginero que se vale de la palabra para irradiar luz sonora y deleite espiritual, está muy por encima de los fragores momentáneos del odio y las bajas pasiones. Esto lo supieron grandes odiadores como Lope de Vega, Walt Whitman, Víctor Hugo y Pablo Neruda y lo sortearon siempre con su inmenso talento. La prueba es que en la memoria colectiva del continente americano permanecen intactos los Veinte poemas de amor, en tanto que ya nadie recuerda esos versículos nerudianos hinchados de rencor y venganza contra un tal Gabriel González Videla.

$$
* * *
$$

Si comparamos cierto fervor -más por curiosidad que por admiración- que en la década de los sesenta todavía se mantenía hacia la actitud rebelde, mas no por la obra, de José María Vargas Vila, con la indiferencia total existente entre los jóvenes de 2010, me da la impresión que su nombre se ha convertido sólo en una referencia en la historia de la literatura colombiana como una actitud periodística y política que marcó un momento estelar de nuestra historia, pero sin una sola señal luminosa que se asome por alguno de sus noventa y ocho libros publicados. Es posible que este vacío responda al certero criterio del poeta y crítico Rafael Maya cuando afirma:

Es necesario que siga el misterio en torno a ciertos escritores y que una leyenda escandalosa los esquive a la gente timorata y constituya un aliciente para los audaces. Es necesario que la fábula de su satanismo mantenga en torno a ellos su siniestro prestigio. Es necesario que el Estado y la Religión los miren con recelo. Si a esos libros se los saca de la clandestinidad y sobre ellos se proyectan las luces de una crítica objetiva y desapasionada, desaparece el misterio y sus autores quedan notablemente disminuidos. Aparece la columna de ladrillo. Pienso que ese puede ser el caso de Vargas Vila. (173)

$* * *$

Vargas Vila es indudablemente un símbolo, si se quiere literario, del talante radical y justiciero contra el oscurantismo de una época dominada por el tradicionalismo conservador, autoritario y clerical, pero en ningún momento es una figura narrativa o ensayística de primer orden. Es cierto que durante largas décadas los estudiantes, las amas de casa, las muchachas del servicio que sabían leer, los proletarios y los rebeldes sempiternos, fueron, a escondidas, lectores devotos y fervorosos de las tres novelas esenciales de Vargas Vila: Ibis, Aura o las violetas y Flor de fango, más por el morbo y por las descripciones descarnadas que por deleite estético. Pero lo cierto es que ninguna

Revista Iberoamericana, Vol. LXXXI, Núm. 252, Julio-Septiembre 2015, 731-739 ISSN 0034-9631 (Impreso) ISSN 2154-4794 (Electrónico) 
de sus obras narrativas (así como tampoco las ensayísticas) señaló un hito importante en la creación literaria nacional.

Sería necio comparar alguna de sus novelas con Manuela de Eugenio Díaz, María de Jorge Isaacs o La vorágine de José Eustasio Rivera, para citar solo a tres autores cardinales de su tiempo. Su estilo ampuloso, un tanto lleno de artificios para adornar el morbo o la dentellada, ensombrecía todo intento de ficción o de belleza creadora. Y como bien lo señala el poeta y ensayista Juan Gustavo Cobo Borda: "Leer una sola novela de Vargas Vila puede resultar divertido; dos es ya exasperante; tres, o más: ignorábamos que usted padeciera en forma tan acentuada, tales ataques de masoquismo" (68). Y agrega:

Todas las novelas de Vargas Vila son iguales: pueriles, simétricas; su tremendismo está compuesto, en verdad, de largas, fatigosas, interminables digresiones en torno a todos los temas; o sea: el tema. El mismo: don José María Vargas Vila. Además, en estas narraciones nunca pasa nada. Previsibles, rutinarias, todas ellas sirven apenas de tribuna a un pontífice iracundo, demorando, lo más posible, el encuentro sexual de los protagonistas. Debido, sobre todo, a que este prolífico calígrafo se regodea en los prolegómenos, en los avances, en los contactos furtivos, en las acechanzas y en los desvíos, creando, por cierto, un suspenso erótico de la peor clase. Un clima que su prosa descoyuntada, sus signos de admiración, sus puntos suspensivos, sus metáforas inverosímiles, sus referencias clásicas, caldean al máximo, sin resolverlo. Por Dios, que suceda algo, cualquier barbaridad, acaba por gritar el lector, irritado. (71)

Vargas Vila ha quedado para la posteridad como un símbolo, lo repito, y quizás, para algunos, como una conciencia de su tiempo, una conciencia crítica, correcta o errada, pero una mala conciencia contra el despotismo y la injusticia en todos los órdenes. Sus adversarios, que eran muchos, contribuyeron a inventar su leyenda negra y de allí que los jóvenes de mi generación en los años sesenta estábamos convencidos que Vargas Vila era un demonio que en vida ya se sabía condenado al fuego eterno; un ateo que blasfemaba contra Cristo y los demás íconos de la religión católica; un pederasta vergonzante; un travesti nocturno en la Bogotá de 1884; un pervertido que habría poseído a su propia madre durante un baile de máscaras; un millonario avaro y amargado; un psicópata egoísta y morboso, en fin, un monstruo con dos pies izquierdos, un flagelo de la patria, un enemigo de Colombia, un engendro extravagante, abominable e infecto.

En tiempos del gobierno de Laureano Gómez, los estudiantes bartolinos inventaron un juego de palabras que decía que no era lo mismo decir "Vargas Vila" que "te las vi largas." Y desde hace algunos años existe en Bogotá un divertido programa radial titulado "El manicomio de Vargas Vil".

-¡Por Dios!- digo yo a estas alturas -¡Para lo que ha quedado Vargas Vila! 


\section{OBRAS CITADAS}

Araújo, Helena. "De 1900 a hoy en Colombia: sitio a la 'Atenas Suramericana"'. Hispamérica 18/53-54 (1989): 35-62.

Borges, Jorge Luis. Historia de la eternidad. Buenos Aires: Emecé Editores, 1989.

Cobo Borda, Juan Gustavo. Lector impenitente. México, D.F.: Fondo de Cultura Económica, 2004.

Gutiérrez Girardot, Rafael. Provocaciones: ensayos. Santafé de Bogotá: Editorial Ariel, 1997.

Jaramillo Agudelo, Darío. "Porfirio Barba-Jacob, 1883-1942. Leyenda negra”. Lecturas Fin de Semana (El Tiempo.com) 4 abril 1999. <http://www.eltiempo.com/archivo/ documento/MAM-887377>. 25 sept. 2013.

López, Luis Carlos. Obra Poética. Caracas: Biblioteca Ayacucho, 1994.

Maya, Rafael. Escritos Literarios. Bogotá: Ediciones de la Revista Ximénez de Quesada, 1968.

Ochoa Moreno, Ernesto. "De la rebeldía al éxtasis". El Colombiano (Medellín, 21 abril 1995): 2D.

Valencia, Guillermo. Obras poéticas completas. Madrid: Aguilar, 1952.

Vallejo, Fernando. El desbarrancadero. Buenos Aires: Alfaguara, 2003.

La puta de Babilonia. Bogotá: Planeta, 2007.

Vargas Vila, José María. Alba roja. Barcelona: R. Sopena, 1919.

Diario secreto. Bogotá: Arango Editores, 1989.

Vásquez, Juan Gabriel. "La diatriba como discurso". Boletín Cultural y Bibliográfico. Biblioteca Luis Ángel Arango 34/45 (1997): 130-131. 
